\title{
Transdermal Application of Steroid to Cervical Trachea for the Cough in Patients with Bronchial Asthma and Cough Variant Asthma-A Pilot Study
}

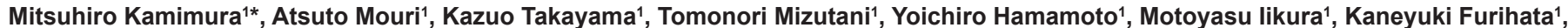
Hiroshi Ishii' and Kenji Sugibayashi

${ }^{1}$ Department of Pulmonology, National Hospital Organization Disaster Medical Center, Japan

${ }^{2}$ Faculty of Pharmaceutical Sciences, Josai University, Japan

\begin{abstract}
Background: The delivery of steroid to asthmatic patients has been limited to inhalation therapy or systemic therapy. The objective of this study was to evaluate the efficacy of transcutaneous application of steroid over the cervical trachea to asthmatic patients as an alternative route of drug delivery.

Methods: Five patients with bronchial asthma (BA), 10 patients with cough-variant asthma (CVA) and 13 patients with cough predominant asthma (CPA) whose symptoms were not adequately controlled despite their current therapy were enrolled in the study. Steroid ointment of mometasone furoate or betamethasone valerate, in the amount of $1 / 2$ fingertip unit once or twice a day for up to 3 months, to the skin over the cervical trachea, was added to the current therapy. Diphenhydramine ointment was also tried by 14 of the study participants.

Results: Out of 28 patients receiving the steroid treatment, cough was reduced in 11 patients (39.3\%). Cough disappeared completely in 3 cases, improved in 7 cases, and reduced temporarily but worsened again during the course in 1 case. Out of 14 patients receiving diphenhydramine treatment, cough was reduced in 5 patients (35.7\%)

Conclusions: The existence of responders to topical steroid ointment therapy to the cervical trachea strongly suggests that the trachea is also involved as an airway inflammation site. Though less effective compared to inhaled corticosteroid therapy, the transdermal administration could be regarded as the third route of steroid therapy for asthmatic cough.
\end{abstract}

Keywords: Betamethasone valerate; Diphenhydramine; Mometasone furoate; Ointment; Tracheitis

\section{Introduction}

Inhaled corticosteroid (ICS) is currently regarded as the mainstay of asthma management and its introduction resulted in a decrease of asthma death [1]. However, complete resolution of the symptoms cannot always be achieved by medication, and oropharyngeal side effects such as hoarseness or stomatitis sometimes develop and result in under-control of the disease due to restriction of the inhalation dose $[2,3]$. Cough receptors are widely distributed in the airway including the trachea, and airway inflammation causes their hypersensitivity $[4,5]$. Not only the bronchus but also the trachea is regarded as an inflammatory site in asthmatic patients [6-8]. Since the trachea is in the lower respiratory tract where direct palpation over the skin is possible, we hypothesized that administration of a topical steroid through the skin could have some effects due to direct distribution of the drug to the tracheal surface for patients who have persistent coughing despite their current medications. We evaluated the efficacy of topical steroid application to the anterior cervix over the trachea in those patients whose cough symptoms were under-controlled with current therapies or because of their restricted use of ICS due to oropharyngeal side effects.

\section{Material and Methods}

The participants in this study consisted of bronchial asthma (BA), cough-variant asthma (CVA) or cough predominant asthma (CPA) patients whose symptoms were not adequately controlled by their current therapy including high-dose ICS, or due to restricted use of ICS due to oropharyngeal side effects such as hoarseness or stomatitis and who were treated at the Pulmonology Department of the National Hospital Organization Disaster Medical Center (Tokyo, Japan) between
January 2006 and June 2007. CVA was defined as a continuous cough for more than 3 weeks with no observed symptomatic or audible wheezing on auscultation that responded to inhalation of $\beta 2$-stimulants, based on the simplified diagnostic criteria for CVA [9]. CPA was defined as a chronic cough with minimal symptoms of wheezing [10]. Those who had dermal diseases at the site of application of the drug were excluded from the study.

Steroid ointment application to the skin over the cervical trachea was added to the current therapy. The area for application was above the upper edge of the sternum, between the right and left sternocleidomastoideus muscles, and below the cricoids cartilage (Figure 1). The amount of steroid ointment used was 1/2 FTU (fingertip unit), about $1 \mathrm{~cm}$ length derived from the tube, once or twice a day for up to 3 months. In some patients, diphenhydramine ointment was also tried. The steroid ointments used were mometasone furoate (Fulmeta Ointment $^{\circledR}, 0.1 \%$, Shionogi, Osaka, Japan) and betamethasone valerate (Rinderon-V Ointment ${ }^{\mathbb{B}}, 0.12 \%$, Shionogi, Osaka, Japan). Half FTU of the ointment contains around $150 \mu \mathrm{g}$ of mometasone furoate or

*Corresponding author: Mitsuhiro Kamimura, Department of Pulmonology, National Hospital Organization Disaster Medical Center, Midori-machi 3256 Tachikawa-shi, Tokyo 190-0014, Japan, Tel: 042-526-5511; Fax: 042-526-5535 E-mail: tdmckamimura@yahoo.co.jp

Received August 01, 2013; Accepted October 11, 2013; Published October 16 2013

Citation: Kamimura M, Mouri A, Takayama K, Mizutani T, Hamamoto Y, et al. (2013) Transdermal Application of Steroid to Cervical Trachea for the Cough in Patients with Bronchial Asthma and Cough Variant Asthma-A Pilot Study. J Allergy Ther 4: 152. doi:10.4172/2155-6121.1000152

Copyright: (c) 2013 Kamimura M, et al. This is an open-access article distributed under the terms of the Creative Commons Attribution License, which permits unrestricted use, distribution, and reproduction in any medium, provided the original author and source are credited. 


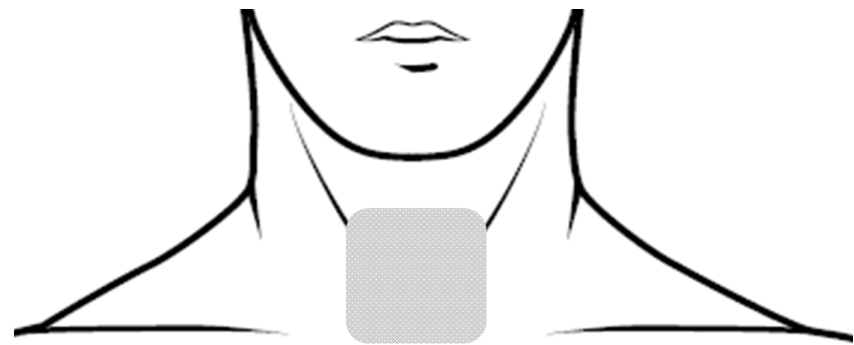

Figure 1: The area of the ointment application.

\begin{tabular}{|c|c|c|c|c|c|c|}
\hline Case & Age/Sex & $\begin{array}{l}\text { Type of a } \\
\text { sthma }\end{array}$ & $\begin{array}{l}\text { Current } \\
\text { medications }\end{array}$ & $\begin{array}{l}\text { Steroid } \\
\text { used }\end{array}$ & Steroid & Diphenhydramin \\
\hline 1 & $32 \mathrm{M}$ & CPA & ICS, AL & MF & $(+)$ & $(+)$ \\
\hline 2 & $62 \mathrm{~F}$ & BA & ICS, LABA, AL, T & MF, BV & $(+)$ & $(+)$ \\
\hline 3 & $57 \mathrm{~F}$ & CPA & ICS, LABA, AL, T & MF & $(+)$ & $(+)$ \\
\hline 4 & $42 \mathrm{~F} \#$ & CVA & ICS, LABA, AL, T & MF & $(+)$ & $(+)$ \\
\hline 5 & $70 \mathrm{~F}$ & CPA & ICS, AL & BV & $(+)$ & $(+)$ \\
\hline 6 & $43 \mathrm{~F}$ & CPA & ICS, LABA, T & MF, BV & $(+)$ & $(-)$ \\
\hline 7 & $62 \mathrm{~F}$ & BA & ICS, AL & MF, BV & $(+)$ & $(-)$ \\
\hline 8 & $62 \mathrm{~F}$ & CPA & ICS, AL & MF, BV & $(+)$ & $(-)$ \\
\hline 9 & $75 \mathrm{M}$ & CPA & LABA, AL, AH, T & BV & $(+)$ & ND \\
\hline 10 & $74 \mathrm{M}$ & CPA & LABA, AL, T & MF, BV & $(+)$ & ND \\
\hline 11 & $33 \mathrm{M}$ & CVA & ICS, LABA & $\mathrm{MF}, \mathrm{BV}^{*}$ & $(+)$ & ND \\
\hline 12 & $71 \mathrm{~F}$ & CVA & ICS, LABA, AL, AH & BV & $(-)$ & $(-)$ \\
\hline 13 & $65 \mathrm{M}$ & BA & LABA, AL, SCS & MF & $(-)$ & $(-)$ \\
\hline 14 & $67 \mathrm{~F}$ & CVA & ICS, LABA & MF, BV & $(-)$ & $(-)$ \\
\hline 15 & $75 \mathrm{~F}$ & CVA & ICS, LABA, AL, T & BV & $(-)$ & $(-)$ \\
\hline 16 & $58 \mathrm{M}$ & CVA & ICS, AH, SAMA & BV & $(-)$ & $(-)$ \\
\hline 17 & $63 \mathrm{~F}$ & CPA & ICS, LABA, T & BV & $(-)$ & $(-)$ \\
\hline 18 & $37 \mathrm{~F}$ & CPA & ICS, LABA, AL, AH & BV & $(-)$ & ND \\
\hline 19 & $80 \mathrm{~F}$ & CVA & ICS, LABA, AL, AH & BV & $(-)$ & ND \\
\hline 20 & $70 \mathrm{~F}$ & BA & ICS, LABA, AL, T & MF & $(-)$ & ND \\
\hline 21 & $64 \mathrm{~F}$ & CPA & ICS, LABA, AL, T & MF & $(-)$ & ND \\
\hline 22 & $30 \mathrm{M}$ & CPA & ICS, LABA, AL & MF & $(-)$ & ND \\
\hline 23 & $27 \mathrm{~F}$ & CVA & ICS, LABA, AL & MF & $(-)$ & ND \\
\hline 24 & $71 \mathrm{~F}$ & CPA & ICS, LABA, AL, T & MF & $(-)$ & ND \\
\hline 25 & $26 \mathrm{M}$ & CPA & ICS, LABA, AH, T & MF & $(-)$ & ND \\
\hline 26 & $68 \mathrm{M}$ & CVA & ICS, LABA, T & MF & $(-)$ & ND \\
\hline 27 & $27 \mathrm{M}$ & CVA & ICS, LABA & MF & $(-)$ & ND \\
\hline 28 & $42 \mathrm{~F}$ & BA & ICS, LABA, AL & MF & $(-)$ & ND \\
\hline
\end{tabular}

BA: Bronchial Asthma; CPA: Cough-Predominant Asthma; CVA: Cough-Variant Asthma; ICS: Inhaled Corticosteroid; LABA: Long Acting Beta Agonist; AL: AntiLeukotriene; AH: Anti-Histamine; T: Theophylline; SCS: Systemic Corticosteroid MF: mometasone furoate; BV: Betamethasone Valerate; (+): Effective; (-): Not Effective; ND: Not Done

*Mometasone furoate effective; betamethasone valerate not effective

\#Diphenhydramin was more effective than MF

Table 1: Characeristic of the patients and the effect of each ointment treatment.

betamethasone valerate. The effect of the treatment was evaluated by the patients' impressions.

Diphenhydramine ointment (Restamin Kowa Cream ${ }^{\circledR}, 1 \%$, Kowa Company, Ltd. Tokyo, Japan) application to the skin over the cervical trachea was also tried in some of the study participants, who were selected randomly. The drug is not tube-contained and approximately the same amount of the drug was taken by the fingertip from the drug container, which was about 0.2-0.3 g containing 2-3 $\mathrm{mg}$ of diphenhydramine.

This study was approved by the ethics committee of the National
Hospital Organization Disaster Medical Center. Each patient was informed about the study before enrollment and gave their consent to participate. This study was registered in the University Hospital Medical Information Network (UMIN) clinical trials registry with registration number UMIN R000008613.

\section{Results}

The steroid ointment was applied in 28 patients (mean age 55.3 \pm 17.5 , female 18) including 5 cases of BA, 13 cases of CPA, and 10 cases of CVA. In four of them the dose of ICS was restricted due to oropharyngeal side effects. The steroid used was mometasone furoate in 20 cases, betamethasone valerate in 15 cases (in 7 cases, both mometasone furoate and betamethasone valerate were used to evaluate the difference of efficacy).

Out of 28 patients receiving the steroid treatment, coughing was reduced in 11 patients (39.3\%) (Table 1 and Figure 2). Cough disappeared completely in 3 patients, improved in 7 patients, and was reduced temporarily but worsened again during the course in 1 patient. The 7 patients who used both mometasone furoate and betamethasone valerate did not report any perceived difference in efficacy except for patient 12 (mometasone furoate effective; betamethasone valerate not effective). In 7 patients, not only the cough but also mild wheezing disappeared after steroid ointment therapy, although moderate wheezing was not controlled.

Among these 28 patients, diphenhydramine ointment was applied in 14 patients including 3 cases of BA, 6 cases of CPA and 5 cases of CVA (Table 1). Out of 14 patients receiving diphenhydramine treatment, coughing was reduced in 5 patients (35.7\%) (Figure 2). All these 5 patients responded to steroid ointment therapy. In 3 patients the steroid ointment therapy was more effective, in one patient the effect of diphenhydramine was equal to that of steroid ointment therapy, and in one patient (case 4) diphenhydramine ointment was more effective than steroid ointment therapy, despite ineffectiveness of oral olopatadine hydrochloride therapy.

The time needed for the patients to feel the improvement of the symptoms ranged approximately from one minute to one hour after the drug application and the duration of the cough suppression effect was generally 3 to 5 hours, according to the patients' impressions.

Side effects such as skin atrophy, telangiectasia, erythema, skin infection were not noted in any patient.

\section{Discussion}

The cervical trachea represents approximately $40 \%$ of the whole trachea and the transdermal approach can cover only its anterior side. The present therapy thus does not cover whole airway inflammation, but the existence of some effective cases supports that the drug can be

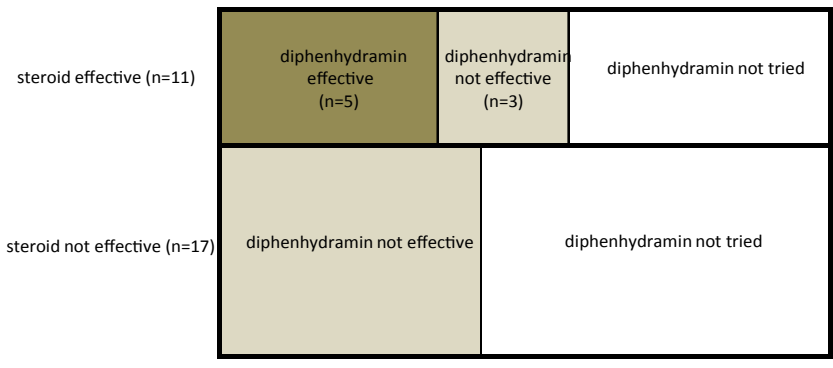

Figure 2: The diagram of the study population $(n=28)$. 
Citation: Kamimura M, Mouri A, Takayama K, Mizutani T, Hamamoto Y, et al. (2013) Transdermal Application of Steroid to Cervical Trachea for the Cough in Patients with Bronchial Asthma and Cough Variant Asthma-A Pilot Study. J Allergy Ther 4: 152. doi:10.4172/2155-6121.1000152

transdermally delivered, at least in some patients, to the trachea, and suggests that tracheitis exists in patients with BA, CPA, and CVA when the patients have cough symptoms. Tracheitis may exist commonly in patients with diseases that cause coughing [6], and also Tanaka et al. demonstrated hypervascularity in both the trachea and bronchi of asthma patients by using high-magnification bronchovideoscopy [7], suggesting the coexistence of tracheitis and bronchitis. Cough receptors are distributed widely throughout the airways from the pharynx to the bronchi $[4,5]$ and become hypersensitive when the nerve terminals are uncovered by loss of epithelial cells due to airway inflammation $[4,5]$.

In non-steroidal anti-inflammatory drugs, direct drug delivery through the skin to the subcutis and underlying muscles $[11,12]$ and to the synovial fluid $[13,14]$ have been reported. Also, the subcutaneous tissue concentration of topically applied steroids under the application site is reported to be higher than the plasma concentration $[15,16]$. The extent of tissue penetration of topically applied drugs may differ among agents, possibly in relation to their lipophilicity and the conditions of ionization at local $\mathrm{pH}$. In a rat model it was about $8 \mathrm{~mm}$ depth for lipophilic steroids (hydrocortisone, fluocinolone acetonide) [15] and 3-4 mm depth for non-steroidal anti-inflammatory drugs [16]. Also, in the rat model, a steroid prodrug (prednisolone sodium succinate) topically applied to the skin over the trachea caused a higher prednisolone concentration at the trachea than in plasma, and the use of iontophoresis resulted in a 12 -fold higher prednisolone concentration at the trachea [17].

The time needed for symptoms improvement after topical application was rather fast ranging from minute to one hour. This might be explained by non-genomic effect of steroid that occurs with a rapid onset within minutes $[18,19]$. This effect is initiated by specific interactions with membrane-bound or cytoplasmic corticosteroid receptors, or nonspecific interactions with the cell membrane [20], and evidence suggests that the corticosteroid decrease airway blood flow by modulating sympathetic control of vascular tone, potentiating noradrenergic neurotransmission in the airway vasculature [21,22].

The effect of the ointment therapy does not seem to be universal, unlike inhaled corticosteroid therapy, but the existence of definite responders to the treatment suggested that topical steroid ointment therapy to the cervical trachea might be considered as a supplemental therapy choice. The factors influencing the efficacy may include differences in the drug permeability at the application site, differences in the inflammation sites in the airway, and differences in degree of inflammation, and should be investigated in a future study. We evaluated two kinds of steroid ointment in 7 cases, mometasone furoate (very strong) and betamethasone valerate (strong), and the effects were almost equal except in one patient who reported mometasone predominance. Considering the possibility of side effects from longterm topical use, it might be better to choose betamethasone for this purpose.

In general, anti-histamines are is not effective for treating BA, but in CVA and atopic cough, which are characterized by chronic bronchodilator-resistant non-productive cough with eosinophilic tracheobronchitis and cough hypersensitivity [23], they are reported to be effective $[23,24]$. Histamine promotes the release of ATP through $\mathrm{H} 1$ receptors and results in hypersensitivity of cough receptors [25]. Antihistamine blocks this pathway and also inhibits the release of substance $\mathrm{P}$ from the C-fiber terminals [26]. In our experience, topical application of diphenhydramine ointment was also effective in a small number of patients and was thought to be effective for treating tracheitis through the above-mentioned mechanism.
The limitations of the study are as follows. The evaluation of the efficacy of the treatment was subjective and the number of patients recruited was small and not blinded, thus the placebo effect cannot be completely excluded. The optimum dose is not yet known and should be estimated in future. Adverse events from long time use of steroid ointment should also be taken into consideration.

\section{Conclusions}

Transdermal application of a steroid to the cervical trachea suppressed the cough in some BA, CPA, and CVA patients. This strongly suggests that the trachea is also involved as an airway inflammation site. The efficacy of the treatment seemed to be limited but the therapy can be considered as a supplementary therapeutic option when patients have cough with an itchy sensation over the anterior neck despite ICS treatment. The results of this pilot case-series study may suggest the necessity of the conduction of randomized placebo-controlled trial, and also additional use of iontophoresis might result in the improvement of the efficacy of the therapy and should be evaluated in a future study.

\section{References}

1. Bateman ED, Hurd SS, Barnes PJ, Bousquet J, Drazen JM, et al. (2008) Globa strategy for asthma management and prevention: GINA executive summary. Eur Respir J 31: 143-178

2. Buhl R (2006) Local oropharyngeal side effects of inhaled corticosteroids in patients with asthma. Allergy 61: 518-526.

3. Bhalla RK, Taylor W, Jones AS, Roland NJ (2008) The inflammation produced by corticosteroid inhalers in the pharynx in asthmatics. Clin Otolaryngol 33 581-586.

4. Widdicombe J (2001) Airway receptors. Respir Physiol 125: 3-15

5. Mazzone SB, Canning BJ (2002) Plasticity of the cough reflex. Eur Respir Rev 12: $236-242$.

6. Kamimura M, Mouri A, Takayama K, Mizutani T, Hamamoto Y, et al. (2010) Cough challenge tests involving mechanical stimulation of the cervical trachea in patients with cough as a leading symptom. Respirology 15: 1244-1251.

7. Tanaka H, Yamada G, Saikai T, Hashimoto M, Tanaka S, et al. (2003) Increased airway vascularity in newly diagnosed asthma using a high-magnification bronchovideoscope. Am J Respir Crit Care Med 168: 1495-1499.

8. Kamimura M, Izumi S, Hamamoto Y, Morita A, Toyota E, et al. (2012) Superiority of nebulized corticosteroids over dry powder inhalers in certain patients with cough variant asthma or cough-predominant asthma. Allergol Int 61: 411-417.

9. Committee for the Japanese Respiratory Society Guidelines for Management of Cough, Kohno S, Ishida T, Uchida Y, Kishimoto H, et al. (2006) The Japanese Respiratory Society guidelines for management of cough. Respirology 11: S135-186.

10. Lalloo UG, Barnes PJ, Chung KF (1996) Pathophysiology and clinical presentations of cough. J Allergy Clin Immunol 98: S91-96.

11. Sugibayashi K, Yanagimoto G, Hayashi T, Seki T, Juni K, et al. (1999) Analysis of skin disposition of flurbiprofen after topical application in hairless rats. J Control Release 62: 193-200.

12. Yanagimoto G, Hayashi T, Hasegawa T, Seki T, Juni K, et al. (1999) Skin disposition of drugs after topical application in hairless rats. Chem Pharm Bull (Tokyo) 47: 749-754

13. Gallacchi G, Marcolongo R (1993) Pharmacokinetics of diclofenac hydroxyethylpyrrolidine (DHEP) plasters in patients with monolateral knee joint effusion. Drugs Exp Clin Res 19: 95-97.

14. Mills PC, Magnusson BM, Cross SE (2005) Penetration of a topically applied nonsteroidal anti-inflammatory drug into local tissues and synovial fluid of dogs. Am J Vet Res 66: 1128-1132.

15. Singh P, Roberts MS (1994) Deep tissue penetration of bases and steroids afte dermal application in rat. J Pharm Pharmacol 46: 956-964.

16. Singh P, Roberts MS (1994) Skin permeability and local tissue concentrations 
Citation: Kamimura M, Mouri A, Takayama K, Mizutani T, Hamamoto Y, et al. (2013) Transdermal Application of Steroid to Cervical Trachea for the Cough in Patients with Bronchial Asthma and Cough Variant Asthma-A Pilot Study. J Allergy Ther 4: 152. doi:10.4172/2155-6121.1000152

of nonsteroidal anti-inflammatory drugs after topical application. J Pharmacol Exp Ther 268: 144-151.

17. Ishii H, Suzuki T, Todo H, Kamimura M, Sugibayashi K (2011) lontophoresisfacilitated delivery of prednisolone through throat skin to the trachea after topical application of its succinate salt. Pharm Res 28: 839-847.

18. Rodrigo GJ (2006) Rapid effects of inhaled corticosteroids in acute asthma: an evidence-based evaluation. Chest 130: 1301-1311.

19. Tillmann HC, Stuck BA, Feuring M, Rossol-Haseroth K, Tran BM, et al. (2004) Delayed genomic and acute nongenomic action of glucocorticosteroids in seasonal allergic rhinitis. Eur J Clin Invest 34: 67-73.

20. Kumar SD, Brieva JL, Danta I, Wanner A (2000) Transient effect of inhaled fluticasone on airway mucosal blood flow in subjects with and without asthma. Am J Respir Crit Care Med 161: 918-921.

21. Mendes ES, Pereira A, Danta I, Duncan RC, Wanner A (2003) Comparative bronchial vasoconstrictive efficacy of inhaled glucocorticosteroids. Eur Respir J 21: 989-993
22. Horvath G, Wanner A (2006) Inhaled corticosteroids: effects on the airway vasculature in bronchial asthma. Eur Respir J 27: 172-187.

23. Fujimura M, Ogawa H, Yasui M, Matsuda T (2000) Eosinophilic tracheobronchitis and airway cough hypersensitivity in chronic non-productive cough. Clin Exp Allergy 30: 41-47.

24. Shioya T, Ito N, Sasaki M, Kagaya M, Sano M, et al. (1996) Cough threshold for capsaicin increases by azelastine in patients with cough-variant asthma. Pulm Pharmacol 9: 59-62.

25. Kamei J, Takahashi Y, Yoshikawa Y, Saitoh A (2005) Involvement of P2X receptor subtypes in ATP-induced enhancement of the cough reflex sensitivity. Eur J Pharmacol 528: 158-161.

26. Kamikawa $Y$ (1989) Inhibitory effect of anti-allergic drugs on cholinergic and non-cholinergic neurotransmissions of guinea pig bronchial muscle in vitro. Ann Allergy 63: 59-63. 